\title{
TINJAUAN HASIL KERAJINAN BATIK CAP DI BATIK SUMUT MEDAN TEMBUNG BERDASARKAN WARNA, MOTIF DAN HARMONISASI
}

\author{
Siti Rama Dhani ${ }^{*}$, Sri Wiratma ${ }^{2 *}$, Misgiya ${ }^{3^{*}}$ \\ Program Studi Pendidikan Seni Rupa Jurusan Seni Rupa Fakultas Bahasa dan Seni \\ Universitas Negeri Medan \\ Jl. Willem Iskandar Pasar V Medan Estate, Kec, Percut Sei Tuan, Kab. Deli Serdang, Kode Pos 20371 \\ Sumatera Utara. Indonesia \\ Email: siti97ramadhani@gmail.com
}

\begin{abstract}
Abstrak
Penelitian ini bertujuan untuk meninjau hasil kerajinan batik cap di Batik Sumut Medan Tembung dengan mengetahui warna batik Sumut, motif batik Sumut dan keharmonisasi pada warna dan motif batik. Metode penelitian menggunakan deskritif kualitatif yakni mengumpulkan berbagai informasi mengenai hasil kerajinan batik cap di Batik Motif Sumut. Populasi dalam penelitian adalah hasil produksi batik cap dengan motif Sumut berjumlah 5 lembar kain jenis batik cap di Batik Motif Sumut di Medan Tembung. Sampel dalam penelitian ini menggunakan Purposive Sampling yakni penentuan sampel dengan pertimbangan tertentu. Guna memperoleh data mengenai tinjauan terhadap batik cap di batik Sumut Medan Tembung. Setelah dilakukan pengumpulan data melalui instrumen penelitian observasi, wawancara dan dokumentasi, maka hasil penelitian menunjukkan hasil dari kerajinan batik cap memiliki motif, warna dan harmonisasi yang berbeda-beda tergantung dari jenis kerajinannya.
\end{abstract}

Kata Kunci: kerajinan batik cap, warna, motif.

\begin{abstract}
This research aims to see the results of stamped batic crafts in the Sumut Medan Tembung batic by knowing the color of North Sumut batic North Sumut batic motifs and harmony. On the colors and motifs of batik. The purpose of the study was to review the results of stamp batk batik North Sumut Medan Tembung by knowing the colors of North Sumut batik North Sumut batik motifs and harmony in the colors and motifs of batik. The population in this study is the results of the production of batik with the motif of North Sumut a mounted to 5 pieces of batik fabric in the type of stamp batik motif North Sumut in Medan Tembung. The sampel in this study used purposive sampling is the determination of the sampel with certain considerations. To obtain data about a review of stamped batik in Sumut Medan Tembung batik. After done data collection through observation research instruments, and documend tation, then the results of the study showed that motifs, colors and different harmonizations depenting on the type of craft.
\end{abstract}

Keywords: stamp batik crafts, colors, motif.

\section{PENDAHULUAN}

Ragam hias di Indonesia merupakan kesatuan dari pola-pola ragam hias daerah atau suku-suku yang telah lama tinggal bahkan berabad-abad di wilayah Indonesia. Berbagai ragam hias yang ada di Indonesia merupakan warisan budaya yang mesti dijaga kelestariannya. Seiring dengan perkembangan zaman maka perkembangan kebudayaan di Indonesia sekarang ini hendaknya juga mengangkat dasar-dasar ragam hias tradisional agar terwujud sebagai bentuk kepribadian bangsa Indonesia.

Pengrajin batik Sumut merupakan salah satu pengrajin batik yang bermotif etnis Sumatera Utara yang beralamat di Kecamatan Medan Tembung. Bila ditinjau dari segi tempat pengrajin batik Sumut sangat sulit diketahui khalayak ramai, karena tidak berada di pusat kota, belum lagi area pekerjaan batik Sumut belum sepenuhnya memadai.

Menurut Sirait (1980 : 1) "Di daerah Sumatera Utara terdapat suku Melayu, Nias dan beberapa suku Batak yang di antaranya adalah: Suku Batak Toba, Simalungun, Karo, Mandailing, dan Pakpak Dairi. Dalam sejarah Indonesia suku-suku tersebut dikenal dengan keanekaragaman keterampilan sebagai suatu media ungkapan makna yang diwujudkan dalam bentuk visual. Bentuk visual inilah yang berperan dalam pengembangan kebudayaan serta mengkomunikasikan nilai-nilai budaya dari masa lampau hingga saat ini. 
Suku Batak masih banyak memiliki sisa kebudayaan dalam struktur sosial maupun kesenian yaitu rumah adat. Ornamen atau ragam hias Batak sering disebut dengan istilah rumah gorga. Seperti daerah Sumatera Utara dalam bahasa Batak Toba, Simalungun dan Mandailing menyebutnya dengan istilah Gorga. Di daerah Karo dan Pakpak Dairi menyebutnya dengan Gerga. Pengungkapan makna dalam gorga adalah pemaknaan secara simbolik. Dimana pewarnaannya menggunakan tiga warna yaitu merah, hitam, dan putih. Teknik peng-gorga-an dilakukan dengan ditoreh atau dicukil (lontik istilah sebutan suku Batak) pada permukaan kayu. Gorga ini juga merupakan suatu pesan hasrat dan nasehat yang bersumber dari pengetahuan, harapan,buah pikiran, sikap perilaku, dan keindahan yang hendak dikomunikasikan. Dilihat dari segi bentuk atau motif dapat dicerminkan falsafah maupun pandangan hidup masyarakat Batak yang suka musyawarah, gotong royong, suka berterus terang, sifat terbuka, dinamis, kreatif dan lain-lain. Motif Batak ini dimaksudkan berupa tanda komunikasi sarat akan, simbol - simbol, pesan, nasehat, dan aturan-aturan dalam masyarakat yang disampaikan lewat motif, diketurunannya, dan bahkan Tuhannya (religious).

\section{KAJIAN TEORI}

\section{Pengertian Tinjauan}

Tinjauan adal Menurut Kamus Bahasa Indonesia (2008 : 1713) "Tinjauan atau meninjau adalah melihat sesuatu yang jauh dari ketinggian atau melihat-lihat (menengok,memeriksa, mengamati, dan sebagainya) a tau mengintai, menyelidiki, melihat, menilik, mempert imbangkan kembali, mempelajari dengan cermat, memeriksa, dan menduga (hati, perasaan, pikiran, dan sebagainya

\section{Pengertian Warna}

Warna adalah salah satu unsur dalam hidup kita yang selalu kita jumpai. Warna dapat didefinisikan secara subyektif (secara psikologis) atau secara obyektif (secara fisik) secara subyektif, warna adalah bagian dari pengalaman indera penglihatan. Secara obyektif, warna merupakan hasil dari panjang gelombang cahaya yang dipancarkan Soewignjo,(2013:2).

\section{Menggambar Menggunakan Pola pada Anak}

Motif merupakan gambaran yang dipakai dalam suatu pembuatan ornamen atau ragam hias, yang mana terdiri dari beberapa bentuk yang alami atau sudah ada sejak dahulu kala dan juga ciptaan manusia pada zaman sekarang. Dalam bukunya Ornamen Nusantara, Sunaryo (2009:8) menjelaskan beberapa tentang motif pada ornamen yaitu motif geometris, tumbuh- tumbuhan, hewan, manusia, kosmos (alam), raksasa, teknologis, kaligrafi dan abstrak. Awal penciptaan motif dimuali dengan desain, Desain adalah dorongan keindahan yang mewujudkan dalam suatu bentuk komposisi; rencana komposisi; suatu yang memiliki kekhasan; atau garis besar suatu komposisi, misalnya bentuk yang berirama, desain motif, komposisi nada, dan lain-lain (Sachari dalam Silalahi, 2018:188).

\section{Pengertian Harmonisasi (Selaras)}

Menurut Sanyoto (2009:213) dalam Nirmana Elemenelemen Seni dan Desain. Kesatuan/keselarasan/Harmony menjadi salah satu prinsip yang penting agar sebuah karya terlihat bagus. Kesatuan/keutuhan adalah kepaduan hubungan antara semua elemen yang disusun dalam sebuah karya. "prinsip kesatuan sesungguhnya ialah adanya saling hubungan antar unsur yang disusun".

\section{Pengertian Batik}

Wulandari (2011:4), dalam Batik Nusantara. "makna filosofis, pembuatan dan industri batik". Secara etimologi, kata batik berasal dari bahasa Jawa, "amba" yang berarti lebar, luas, kain; dan "titik" yang berarti titik atau matik (kata kerja membuat titik) yang kemudian berkembang menjadi istila batik, yang berarti menghubungkan titik menjadi gambar tertentu pada ka in yang luas atau lebar. Batik juga mempunyai pengertian segala sesuatu yang berhubungan dengan membuat titik-titik tertentu pada kain mori.

\section{METODE PENELITIAN}

Metode yang digunakan dalam penelitian ini adalah deskriptif kualitatif. Teknik pengumpulan data yang digunakan observasi, wawancara dan dokumentasi. Instrumen peneltian yang digunkan yaitu buku catatan, kamera dan daftar pertanyaan. Teknik analisis data yang digunakan yaitu deskriptif kualitatif.

\section{HASIL DAN PEMBAHASAN \\ 1.Hasil}

Data yang dikemukakan dalam penelitian ini adalah data kualitatif yang merupakan gambaran dari hasil penelitian yang ada dilapangan, kemudian dideskripsikan untuk memperoleh hasil penelitian. Berdasarkan hasil penelitian dilapangan yang meneliti hasil produksi kain batik jenis cap dengan motif Sumut di Batik Motif Sumut Medan Tembung. Data yang diperoleh dalam penelitian ini adalah hasil tinjauan kain batik jenis cap dengan motif Sumut, sebanyak 5 lembar kain batik. Mengetahui hasil dokumentasi hasil kerajinan batik cap di batik Sumut Medan Tembung yang ditinjau dari warna, motiif dan harmonisasi. Maka seluruh data yang terkumpul dan 


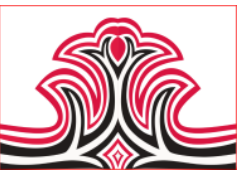

diperoleh akan ditinjau berdasarkan dokumentasi foto kain batik cap dengan Motif Sumut. Motif Sumut tersebut dibuat dengan menggunakan alat dan bahan batik dengan teknik cap yang merupakan teknik pembuatan batik yang dianggap lebih efisien pada saat ini untuk membuat karya seni Batik di Sumatera Utara. Jenis motif yang diterapkan adalah motif Melayu, Nias dan, Simalungun.

\section{Pembahasan}

\section{1). Karya 1}

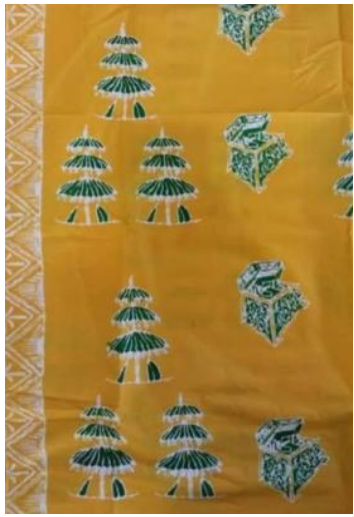

Gambar 1. Batik Motif Payung, Tepak Sirih Dan Belah Ketupat. (Sumber: Siti Rama Dhani, 2020)

\section{(1). Motif yang Diterapkan pada Kain}

Pada batik 1 ini jenis motif yang diterapkan adalah Payung, Tepak Sirih dan Belah Ketupat motif yang berasal dari motif Melayu. Penempatan motif Payung, Tepak Sirih dan Belah Ketupat disusum berbaris memanjang pada kain. Belah Ketupat ditempatkan di pinggir sebelah kiri dari susunan motif Payung, dan Tepak Siri. Bentuk pola komposisi dalam penerapan motif pada batik 1 ini adalah proses pengulangan bentuk secara sejajar vertikal. Bentuk - bentuk Payung, Tepak Siri disusun dalam kedudukan yang serupa dan jarak yang sama, sedangkan motif Belah Ketupat di susun di pinggir kiri dari susunan motif Belah Ketupat.

\section{(2). Perpaduan Warna Motif pada Kain}

Warna yang digunakan adalah warna kuning, hijau dan putih sesuai dengan warna motif melayu. Pada batik 1 ini warna putih digunakan pada garis di motif Payung, Tepak Siri dan Belah Ketupat. Warna hijau digunakan untuk bidang Motif Payung dan Tepak Sirih dan warna kuning digunakan sebagai warna dasar pada batik 1 ini. warna putih adalah warna yang memberi kesan bersih, didalam dunia warna mode warna putih adalah termasuk warna yang elegan, Warna hijau memberi kesan kesuburan, kesegaran, kedamaian dan keseimbangan. Warna kuning mengarah pada warna yang paling bahagia, menyolok dan warna kuning memberi arti kehangatan dan rasa bahagia,
Gorga : Jurnal Seni Rupa

Volume 09 Nomor 01 Januari-Juni 2020

p-ISSN: 2301-5942 | e-ISSN: 2580-2380

\section{(3). Keharmonisan Motif dan Warna pada Kain}

Seperti yang terlihat pada gambar di atas, susunan motif dibuat dengan bentuk secara sejajar vertikal, dilihat dari keseluruhan kain tersebut sudah dapat dikatakan harmonis dalam pemilihan warna dan motif. Warna yang di gunakan sangat sesuai dengan warna asli pada warna motif Melayu dan perpaduan motif yang sederhana membuat kain batik 1 ini sangat serasi dan indah dengan motif yang sederhana. Motif di atas menggunakan motif dari Melayu.

\section{2). Karya 2}

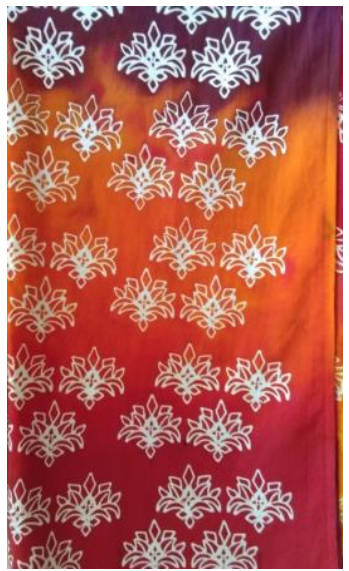

Gambar 2. Batik Motif Tunas Bersusun. (Sumber : Siti Rama Dhani, 2020)

\section{(1). Motif yang Diterapkan pada Kain}

Pada batik 2 ini jenis motif Melayu yang digunakan adalah motif Tunas Bersusun yang bersal dari Melayu. Penempatan Tunas Bersusun disusun memanjang pada kain. Bentuk pola komposisi dalam penempatan motif pada batik 2 ini adalah proses pengulangan bentuk secara sejajar horizontal. Bentuk-bentuk Tunas Bersusun disusun dalam kedudukan yang serupa dan jarak yang sama. Tunas Bersusun adalah budi luhur perangai santun hidup kekal turun temurun rezeki melimpah sepanjang tahun.

\section{(2). Perpaduan Warna Motif pada Kain}

Warna yang digunakan pada motif batik 2 ini adalah ungu, orange, putih, kuning, pink dan merah tidak sesuai dengan warna motif Melayu. Warna putih digunakan pada pada garis di motif Tunas Bersusun dan warna ungu, orange, kuning, pink dan merah digunakan sebagai warna dasar pada batik 2 ini. Penggabungan antar keenam warna tersebut sangat pas begitu juga dengan kombinasi yang dipilih yaitu warna ungu memberi kesan warna mewah, keagungan dan kebijaksanaan, warna orange adalah memberi kesan kehangatan, kenyamanan dan keceriaan, pada warna putih adalah warna yang memberi kesan bersih, didalam dunia warna mode warna putih adalah termasuk warna yang elegan, warna kuning mengarah 


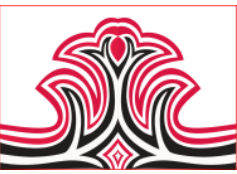

pada warna yang paling bahagia, menyolok dan warna kuning memberi arti kehangatan dan rasa bahagia, warna pink maknanya warna ini merepresentasikan prinsip feminim dan banyak disukai wanita, dan warna merah selalu menarik perhatian memiliki karakteristik merangsang, memperkuat motivasi, dan membangkitkan emosi. Warna yang digunakan pada warna motif batik 2 ini adalah warna sekunder.

\section{(3). Keharmonisan Motif dan Warna pada Kain}

Pada gambar di atas terlihat kain yang memiliki motif secara keseluruhan terlihat harmonis dan cantik, meski motif yang terlihan motif yang sederhana dan monoton. Bentuk kain dengan peletakan motif sangatlah bagus. Pada kain terdapat motif di dalam satu kain yaitu motif Tunas Bersusun pola komposisi dalam penerapan motif batik 2 ini adalah proses pengulangan bentuk secara sejajar horizontal. Dari segi warna dapat dikatakan harmonis meski warna di dalam kain motif Melayu ini tidak sesuai dan banyak terdapat warna didalamnya dan warna yang digunakan masih terkesan sejuk dan indah dilihat dengan dipilihnya warna - warna sekunder. Warna yang terdapat pada kain batik terlihat indah. Penyusunan atau peletakan motif juga harmonis diletakan dengan posisi horizontal.

\section{3). Karya 3}

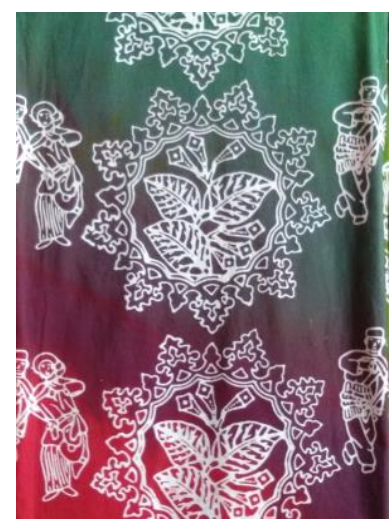

Gambar 3 Batik Penari Serampang Dua Belas Dan Daun Tembakau Deli

(Sumber : Siti Rama Dhani 2020)

\section{(1). Motif yang Diterapkan pada Kain}

Pada batik 3 ini jenis motif Melayu yang digunakan adalah motif Penari Serampang Duabelas dan Daun Tembakau Deli yang bersal dari Melayu. Penempatan Penari Serampang Duabelas dan Daun Tembakau Deli disusun memanjang pada kain. Bentuk pola komposisi dalam penempatan motif pada batik 3 ini adalah proses pengulangan bentuk secara sejajar vertikal. Bentuk -bentuk Penari Serampang Duabelas dan Daun Tembakau Deli disusun dalam kedudukan yang serupa dan jarak yang sama. Penari Serampang
Gorga : Jurnal Seni Rupa

Volume 09 Nomor 01 Januari-Juni 2020

p-ISSN: 2301-5942 | e-ISSN: 2580-2380

Duabelas menceritakan tahap percintaan sepasang kekasin dan Daun Tembakau merupakan tanaman musiman yang ditanam pada menjelang musim kemarau.

\section{(2). Perpaduan Warna Motif pada Kain}

Pada gambar di atas terlihat kain yang memiliki motif secara keseluruhan terlihat harmonis dan cantik, dengan perpaduan motif Penari Serampang Duabelas dan Daun Tembakau Deli. pola komposisi dalam penerapan motif batik 3 ini adalah proses pengulangan bentuk secara sejajar vertikal. Dari segi warna dapat dikatakan harmonis meski warna di dalam kain motif Melayu ini, tidak sesuai dan banyak terdapat warna didalamnya dan warna yang digunakan masih terkesan indah dilihat dengan dipilihnya warna - warna sekunder. Warna yang terdapat pada kain batik terlihat indah. Penyusunan atau peletakan motif juga harmonis diletakan dengan posisi vertikal.

\section{4). Karya 4}

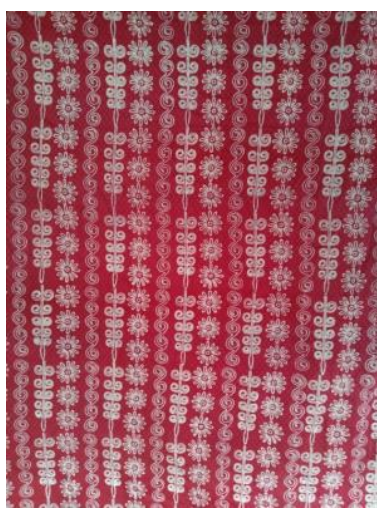

Gambar 4.4 Batik Motif Niosolafiga, Niotalinga Woli-Woli, dan Nioafi-afi motif

(Sumber : Siti Rama Dhani 2020)

\section{(1).Motif yang Diterapkan pada Kain}

Pada batik 4 ini jenis motif Batak yang diterapkan adalah Niosolafiga, Niotalinga Woli-Woli, dan Nioafiafi motif yang berasal dari motif Nias. Penempatan motif Niosolafiga, Niotalinga Woli-Woli, dan Nioafiafi disusun berbaris memanjang pada kain. Bentuk pola dan komposisi dalam penerapan motif pada Batik 4 ini adalah pengulangan bentuk secara vertikal. Bentuk - bentuk Niosolafiga, Niotalinga Woli-Woli, dan Nioafi-afi disusun dalam kedudukan yang serupa dan jarak yang sama. Niosolafiga melambangkan persatuan dan sifat gotong royong dari masyarakat, Nioafi-afi melambangkan keberadaan atau kebangsawan, dan Niotalinga Woli-Woli menyerupai tumbuhan pakis yang melambangkan kesuburan.

\section{(2). Perpaduan Warna Motif pada Kain}

Warna motif Nias seperti yang kita ketahui yaitu merah, hitam, putih dan kuning, seperti pada gambar 


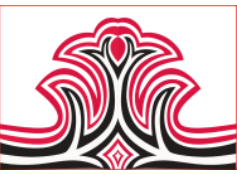

di atas, pengrajin memadukan warna motif nias yaitu, merah dan putih dengan bahan dasar kain. Dengan perpaduan tersebut akan memperkuat makna yang terkandung dalam motif tersebut. Pada motif di atas terdapat warna yang digunakan adalah warna merah, dan putih sesuai dengan warna motif Nias. Pada batik 4 ini warna putih digunakan pada bidang motif Niosolafiga, NiotalingaWoli-Woli, dan Nioafiafi motif, warna merah digunakan sebagai warna dasar pada batik 4 ini. Warna merah selalu menarik perhatian memiliki karakteristik merangsang, memperkuat motivasi, dan membangkitkan emosi. Terlihat juga bahwa perpaduan warna yang digunakan agar sesuai dengan makna dan nilai - nilai filosofi motif tersebut. Motif yang digunakan pengrajin adalah motif jenis Niosolafiga yang melambangkan persatuan dan sifat gotong royong dari masyarakat nias, Niotalinga Woli-Woli yang melambangkan kesuburan, dan Nioafi-afi yang melambangkan keberadaan atau kebangsawan dari sipemiliknya.

\section{(3). Keharmonisan Motif dan Warna pada Kain}

Pada gambar di atas terlihat kain yang memiliki perpaduan motif secara keseluruhan terlihat sangat cantik, elegan dan menarik. Bentuk kain dengan peletakan motif sangatlah bagus. Pada kain terdapat beberapa motif di dalam satu kain yaitu motif Niosolafiga, Niotalinga Woli-Woli, dan Nioafi-afi. Bentuk pola komposisi dalam penerapan motif batik 4 ini adalah proses pengulangan bentuk secara sejajar Vertikal. Dari segi warna dapat dikatakan harmonis karena tidak ada warna yang berbenturan. Warna yang terdapat pada kain batik terlihat indah. Keharmonisan yang terdapat pada batik 4 di atas dapat dikatakan harmonis.

\section{5). Karya 5}

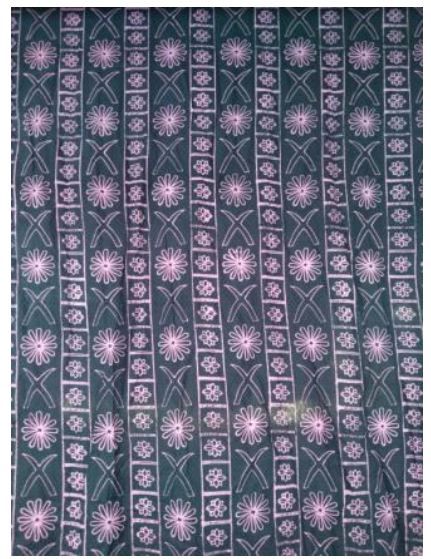

Gambar 5. Batik Motif Nioafi-afi, Nioiozasai , Bunga Hambili (Sumber : Siti Rama Dhani 2019)
Gorga : Jurnal Seni Rupa

Volume 09 Nomor 01 Januari-Juni 2020

p-ISSN: 2301-5942 | e-ISSN: 2580-2380

\section{(1). Motif yang Diterapkan pada Kain}

Pada batik 5 ini jenis motif yang diterapkan adalah yang berasal dari motif Nias dan Simalungun. Penerapan motif Nioafi-afi, Nioiozasai motif yang berasal dari Nias dan Bunga Hambili motif yang berasal dari Simalungun disusun berbaris memanjang pada kain. Bentuk pola dan komposisi dalam penerapan motif pada Batik 5 ini adalah pengulangan bentuk secara sejajar vertikal. Bentuk - bentuk Nioafiafi, Nioiozasai dan Bunga Hambili disusun dalam kedudukan yang serupa dan jarak yang sama. Nioafiafi melambangkan persatuan dan sifat gotong royong dari masyarakat Nias, Nioiozasai menyerupai bulu ekor burung. Melambangkan seorang pahlawan, dan Bunga Hambili motif ini dianggap sebagai simbol penghematan untuk kehidupan.

\section{(2). Perpaduan Warna Motif pada Kain}

Warna motif pada batik di atas, pengrajin memadukan warna motif nias yaitu, hitam dan putih dengan bahan dasar kain. Dengan perpaduan tersebut akan memperkuat makna yang terkandung dalam motif tersebut. Pada motif di atas terdapat warna yang digunakan adalah warna putih, warna putih sesuai dengan warna motif Nias dan Simalungun. Pada batik 5 ini warna putih digunakan pada bidang motif Nioafiafi, Nioiozasai dan BungaHambili warna hitam digunakan sebagai warna dasar pada batik 5 ini. Warna putih adalah warna yang memberi kesan bersih, identik memberi kesan damai, dan kesederhanaan. Didalam dunia mode, warna putih akan terlihat elegan dan indah dengan penggabungan warna - warna lain, dan warna hitam memberi kesan suram, misterius, dan menakutkan tetapi warna hitam juga termasuk warna yang elegan.

\section{(3). Keharmonisan Motif dan Warna pada Kain}

Pada gambar di atas terlihat kain yang memiliki perpaduan secara keseluruhan terlihat sangat cantik, elegan dan menarik. Bentuk kain yang panjang dengan peletakan motif sangatlah bagus perpaduan secara keseluruan dapat dikatakan harmonis. Penyusunan motif pola vertikal juga terlihat menarik untuk dilihat. Pemilihan warna senada. Kombinasi yang digunakan pada kain.

\section{Pembahasan}

Data yang dikemukakan dalam penelitian ini adalah data kualitatif yang merupakan gambaran dari hasil penelitian yang ada dilapangan, kemudian dideskripsikan untuk memperoleh hasil penelitian. Berdasarkan hasil penelitian dilapangan yang meneliti 


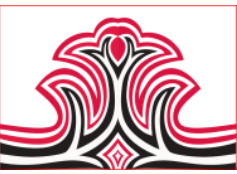

hasil produksi kain batik jenis cap dengan motif Sumut di Batik Motif Sumut Medan Tembung.

\section{KESIMPULAN DAN SARAN}

\section{Kesimpulan}

Setelah data diperoleh, diolah, dan ditinjau kemudian diperoleh beberapa kesimpulan penelitian sebagai berikut : Pada umumnya warna yang digunakan pada batik dengan motif Sumut adalah warna - warna yang sesuai pada warna aslinya seperti Melayu warna aslinya hijau,kuning, Nias dengan warna aslinya yaitu kuning, merah, hitam. Motif Sumut yang ada pada kelimah batik ini adalah jenis motif Payung, Tepak Sirih dan Belah Ketupat motif yang berasal dari motif Melayu. Tunas Bersusun yang bersal dari Melayu. Serampang Duabelas dan Daun Tembakau Deli yang bersal dari Melayu. Niosolafiga, Niotalinga WoliWoli, dan Nioafi-afi motif yang berasal dari motif Nias. Nioafi-afi, Nioiozasai Nioafi-afi, Nioiozasai dan Bunga Hambili yang berasal dari motif Simalungun.

Secara keseluruhan harmonisasi warna dan motif dapat dilihat harmonis (selaras), karena perpaduan warna yang dipilih saling menguatkan dan motif yang dilih adalah motif-motif yang sesuai. Meski warna yang di pilih tidak sesuai warna aslinya, namun warna yang dipilih pun masih terlihat harmonis dilihat dan tidak membuat mata sakit saat melihat kain batik tersebut. dan untuk peletakan motif proporsi dan komposisi juga di pilih yang sesuai dengan bentuknya, ada yang vertikal dan juga ada yang horizontal sehingga motif terlihat harmonis.

\section{Saran}

Berdasarkan hasil penelitian dan kesimpulan diatas, maka disampaikan beberapa saran antara lain : Dalam penerapan motif Sumat hasil karya Batik Motif Sumut perlu terlebih dahulu adanya pengenalan dan pemahaman akan motif - motif Sumatra Utaran Pengrajin perlu terlebih dahulu banyak bereksplorasi untuk meningkatkan kreatifitas. Seharusnya motif yang diterapkan pada Batik di Rumah Batik Motif Sumut lebih diperbanyak campuran jenis motif Sumut pada selembar kain tersebut. Dalam proses penciptaan karya batik dengan motif Sumut sebelumnya diawali dengan evaluasi desain untuk mengantisipasi kemungkinanan hasil yang kurang baik dalam pembuatan karya batik dengan motif Sumut. Seharusnya karya batik dengan motif Sumut yang dihasilkan pada Batik Motif Sumut tidak hanya difungsikan untuk kebutuhan sandang saja tetapi dapat difungsikan sebagai kebutuhan hiasan seperti interior ruangan (lukisan batik, kain pelapis sofa/upholstery, bantals sofa/cushion, taplak meja, penutup jendela,
Gorga : Jurnal Seni Rupa

Volume 09 Nomor 01 Januari-Juni 2020

p-ISSN: 2301-5942 | e-ISSN: 2580-2380

wallpaper dinding), kendaraan umum di kota Medan dengan motif batik khas motif Sumut. Agar penelitian ini tidak hanya sampai disini saja, diharapkan adanya penelitian lanjutan lagi supaya seni budaya itu sendiri semakin disukai dan diminati untuk diketengahkan Kepada masyarakat Provinsi Sumatra Utara seacara Khusus generasi muda agar tetap memilihara dan menjaga serta mengembangkan batik dengan motif Sumatra yang sudah ada agar tidak punah dengan majunya zaman serta memperkenalkan kepada masyarakat luar baik dalam Negeri maupun Luar Negeri.

\section{DAFTAR RUJUKAN}

Bahasa, Kamus Pusat, (2008) Kamus Bahasa Indonesia. Jakarta : Pusat Bahasa.

Sanyoto, sadjiman Ebdi. (2009) Nirmana:Elemenelemen Seni dan Desain (edisi ke-2). Yogyakarta: Jalasutra.

Silalahi, D., Saragi, D., Cerah, A., Azis, K., \& Sugito. (2018). Tinjauan Prinsip-Prinsip Desain Pertamanan pada Masjid Taman Wisata Iman Sitinjo Kabupaten Dairi. Gorga Jurnal Seni Rupa Unimed, 8(1), 187-191. Retrieved from https://jurnal.unimed.ac.id/2012/index.php/go rga/article/view/13028/11071.

Sirait, Baginda. (1980) Pengumpulan dan

Dokumentasi Ornamen Tradisional di

Sumatra Utara, Medan: IKIP Medan.

Soewignjo, Santosa. ( 2013) Seni Mengatur

Komposisi Warna Digital. Yogyakarta

Penerbit PT. Macananjaya Cemerlang.

Sunaryo, Aryo, (2009) Ornamen Nusantara Kajian khusus Tentang Ornamen Indonesia. Semarang: Dhara Prize.

Wulandari, Ari. (2011) "Batik Nusantara", Makna Filosofis Cara Pembuatan dan Industry Batik. Yogyakarta : C.V Andi Offset. 